\author{
Pedro Silveira $\cdot$ Manuel Vaz-da-Silva $\cdot$ Luis Almeida \\ Joana Maia · Amilcar Falcão · Ana Loureiro \\ Leonel Torrão $\cdot$ Rita Machado $\cdot$ Lyndon Wright \\ Patrício Soares-da-Silva
}

\title{
Pharmacokinetic-pharmacodynamic interaction between BIA 3-202, a novel COMT inhibitor, and levodopa/benserazide
}

\author{
Received: 13 June 2003 / Accepted: 30 July 2003/Published online: 27 September 2003
}

(C) Springer-Verlag 2003

\begin{abstract}
BIA 3-202 is a novel catechol-O-methyltransferase (COMT) inhibitor being developed for use as a levodopa-sparing agent in Parkinson's disease. This study investigated the effect of four single oral doses of BIA 3-202 (50 mg, $100 \mathrm{mg}, 200 \mathrm{mg}$, and $400 \mathrm{mg}$ ) compared with placebo on plasma concentrations of levodopa and its metabolite 3-O-methyl-levodopa (3-OMD) and on inhibition of erythrocyte COMT in healthy subjects receiving $100 \mathrm{mg}$ of levodopa and $25 \mathrm{mg}$ of benserazide (Madopar 125). This was a single-centre, double-blind, placebo-controlled, randomised, crossover study with five single-dose treatment periods. The washout period between doses was 2 weeks. On each treatment period, a different dose of BIA 3-202 or placebo was administered concomitantly with Madopar 125. Tolerability was assessed by recording adverse events, vital signs, continuous electrocardiogram and clinical laboratory parameters. In the study, 18 subjects (12 male and 6 female) participated. The drug combination was well tolerated. All doses of BIA 3-202 significantly increased the area under the concentration-time curve (AUC) versus placebo, ranging from $39 \%$ (95\% confidence intervals, $1.06-1.69)$ with $50 \mathrm{mg}$ to $80 \%$ (95\% confidence intervals, $1.42-2.22)$ with $400 \mathrm{mg}$. No significant change in mean maximum plasma concentrations $\left(\mathrm{C}_{\max }\right)$ of levodopa was found. Mean $\mathrm{C}_{\max }$ and AUC of 3-OMD significantly decreased for all doses tested. BIA 3-202 caused a rapid and reversible inhibition of S-COMT activity, ranging from $57 \%(50 \mathrm{mg})$ to $84 \%(400 \mathrm{mg})$. In conclusion, the
\end{abstract}

P. Silveira · M. Vaz-da-Silva $\cdot$ L. Almeida $\cdot$ J. Maia

A. Loureiro $\cdot$ L. Torrão $\cdot$ R. Machado $\cdot$ L. Wright

P. Soares-da-Silva $(\bowtie)$

Department of Research and Development,

BIAL, Á Av. da Siderurgia Nacional,

4745-457 S. Mamede do Coronado, Portugal

E-mail: Psoares.silva@bial.com

Tel.: + 351-22-9866100

Fax: + 351-22-9866192

A. Falcão

Laboratory of Pharmacology, Faculty of Pharmacy, University of Coimbra, 3000-295 Coimbra, Portugal novel COMT inhibitor BIA 3-202 was well tolerated and significantly increased the bioavailability of levodopa and reduced the formation of 3-OMD when administered with standard release levodopa/benserazide.

Keywords Catechol- $O$-methyltransferase $\cdot$ COMT inhibition P Pharmacokinetics

\section{Introduction}

Parkinson's disease is an age-related neurodegenerative disorder that affects approximately $1 \%$ of people aged over 60 years and accounts for approximately $75 \%$ of demand of services in movement-disorder clinics $[1,2,3]$. Despite the introduction of new antiparkinsonian drugs in the last decade, the most effective therapy in Parkinson's disease is still levodopa, the immediate precursor of dopamine [2]. In order to prevent its metabolism by aromatic L-amino acid decarboxylase (AADC) to dopamine in the periphery, levodopa is routinely administered in combination with an AADC inhibitor (benserazide or carbidopa). However, when administered with carbidopa or benserazide, a considerable amount of levodopa is converted to 3-O-methyl-levodopa (3-OMD) by peripheral catechol- $O$-methyltransferase (COMT), and only one-tenth of the administered dose reaches the brain [4]. The rationale behind the use of COMT inhibitors in combination with levodopa/ benserazide or levodopa/carbidopa is to (i) increase the levodopa availability to the brain, while inhibiting the peripheral $O$-methylation of levodopa, (ii) improve the transport of levodopa across the blood-brain barrier, since 3-OMD competes with levodopa for transport into the brain [5] and (iii) reduce fluctuations in plasma and brain levels of levodopa, avoiding the exposure of brain dopamine receptors to alternating high and low concentrations of dopamine [2]. In fact, improved stability of levodopa plasma levels may reduce the risk for the development of motor complications [6, 7]. The COMT 
inhibitors clinically developed to date are tolcapone and entacapone. Tolcapone has been withdrawn from many countries due to hepatotoxicity. In the USA, the clinical use of tolcapone requires close monitoring of liver function. No cases of liver dysfunction have been attributed to entacapone, but its effectiveness as an adjunct to levodopa therapy in Parkinson's disease is generally considered to be lower than that for tolcapone $[8,9,10]$. Another difference between tolcapone and entacapone is that the former crosses the blood-brain barrier and inhibits COMT both in the periphery and brain, whereas entacapone is a selective peripheral COMT inhibitor [11]. However, the usefulness of inhibition of brain COMT has not been established for the treatment of Parkinson's disease [12].

BIA 3-202 (1-[3,4-dihydroxy-5-nitrophenyl]-2-phenyl-1-ethanone) is a novel COMT inhibitor currently under clinical development. Studies in laboratory animals have shown that BIA 3-202 is much more potent at inhibiting COMT in the periphery than in the brain [13, 14]. In liver homogenates from rats administered orally with BIA 3-202, tolcapone or entacapone, BIA 3-202 was found to be equipotent with tolcapone in inhibiting liver COMT, this being more sustained and intense than that with entacapone [14]. At $t_{\max }$, inhibition of liver COMT was similar for BIA 3-202 and tolcapone, but BIA 3-202 was clearly less potent than tolcapone in inhibiting brain COMT [14]. In several animal models, concomitant administration of BIA 3-202 with levodopa plus benserazide increased in a time- and dose-dependent manner the availability of levodopa to the brain, this being accompanied with increases in plasma levodopa AUC values $[15,16,17]$. In an entry-into-man study in healthy male subjects, single doses of 10 $800 \mathrm{mg}$ BIA 3-202 were well tolerated [18]. The safety profile did not differ from that of placebo. Systemic exposure to BIA 3-202 increased in an approximately dose-proportional manner. Food did not affect BIA 3202 bioavailability. A good safety profile was also shown in a multiple dose study in healthy volunteers administered with four dosing regimens $(50 \mathrm{mg}$ b.i.d., $100 \mathrm{mg}$ b.i.d., 200 b.i.d., and $200 \mathrm{mg}$ t.i.d.) of BIA 3-202 for 8 days (Almeida and Soares-da-Silva, unpublished observations). Safety parameters did not differ from placebo. BIA 3-202 reduced soluble COMT (S-COMT) activity in erythrocytes, in a dose-dependent manner.

The aim of the present study was to investigate the tolerability and the pharmacokinetic and pharmacodynamic (inhibition of erythrocyte S-COMT activity) interactions between standard release $100 / 25 \mathrm{mg}$ levodopa/benserazide and single oral doses of $50 \mathrm{mg}, 100 \mathrm{mg}$, $200 \mathrm{mg}, 400 \mathrm{mg}$ of BIA 3-202 in healthy subjects.

\section{Methods}

Study design and ethics compliance

This was a double-blind, randomised, placebo-controlled, crossover study with five single-dose treatment periods, with washout periods of approximately 2 weeks between doses. The study was conducted at BIAL's Human Pharmacology Unit (S. Mamede do Coronado, Portugal) according to the principles of the Declaration of Helsinki and the Good Clinical Practice (ICH) guidelines. An independent ethics committee (Comissão de Ética Independente da UFH, Porto, Portugal) reviewed and approved the study protocol and supervised the study activities. Written informed consent was obtained for each volunteers prior to enrolment in the study. Volunteers were admitted to the unit approximately $24 \mathrm{~h}$ prior to receiving the study medication and remained in the unit under clinical observation for at least $30 \mathrm{~h}$ post-dose, in each treatment period. All subjects attended the five treatment periods and, in each period, randomly received a different dose of BIA 3-202 or placebo. Tablets of 50, 100, 200 and $400 \mathrm{mg}$ BIA 3-202, and placebo tablets identical in appearance were used. Tablets containing BIA 3-202 were manufactured by BIAL (S. Mamede do Coronado, Portugal) in accordance with Good Manufacturing Practice. Standard-release 100/25 mg levodopa/benserazide tablets (Madopar 125, Roche Farmacêutica Química, Amadora, Portugal) were administered concomitantly with BIA 3-202.

Subjects

Eighteen healthy male and female volunteers aged 18-45 years and with a body mass index of $19-28 \mathrm{~kg} / \mathrm{m}^{2}$ participated in the study. The healthy status was assessed on the basis of a medical history, physical examination, electrocardiogram (ECG), and clinical laboratory safety tests (haematology, coagulation, plasma biochemistry, urinalysis, and hepatitis B, hepatitis C and HIV serology). Tests for drugs of abuse, and a pregnancy test in females, were performed at screening and each admission. Though it is known that BIA 3-202 was devoid of teratogenic effects in laboratory animals (BIAL's data on file), females were required to use effective contraceptive methods throughout the study. No concomitant medication was allowed during the study, except if required for treatment of adverse events. During in-house staying, a standard diet was served and alcohol-, caffeine- and grapefruit-containing food and beverages were prohibited. Smoking was not allowed.

\section{Assessment procedures}

At screening, a complete medical history and physical examination were performed and updated at each admission. During each admission, supine and standing blood pressure, heart rate and a brief neurological examination were obtained at frequent intervals; continuous lead-II ECG monitoring was performed $0-4 \mathrm{~h}$ postdose; 12-lead ECG recordings were obtained at pre-dose, and $1 \mathrm{~h}$ and $30 \mathrm{~h}$ post-dose. Clinical laboratory tests (haematology, plasma biochemistry, and urinalysis) were performed at each admission and $24 \mathrm{~h}$ post-each dose. A follow-up visit occurred approximately 2 weeks after last dosing; then, the medical history and physical examination were updated, and 12-lead ECG and clinical laboratory safety tests were performed.

All clinical adverse events were monitored throughout the entire study period. Their severity (intensity) was categorised according to a three-point scale (mild, moderate, and severe) and the causality (potential relationship to drug) was assessed by the investigator before breaking the blinding.

\section{Blood sampling and assay of plasma levodopa and 3-OMD}

In each treatment period, blood samples $(10 \mathrm{ml})$ were taken predose and at $0.5,1,1.5,2,3,4,6,8,12,18$ and $24 \mathrm{~h}$ post-dose. Blood samples were drawn either by direct venipuncture or via an intravenous catheter. Blood samples were taken into vacutainers containing potassium ethylene diamine tetraacetic acid (EDTA) and centrifuged immediately $\left(1500 \times g, 10 \mathrm{~min}, 4^{\circ} \mathrm{C}\right)$. The resulting plasma was separated into six $0.8-\mathrm{ml}$ aliquots and stored at $-70^{\circ} \mathrm{C}$ 
until required for analysis. Plasma concentrations of levodopa and 3-OMD were assayed by the Laboratory of Pharmacological Research, BIAL (S Mamede do Coronado, Portugal), using a validated method. Briefly, samples were allowed to thaw at room temperature and an aliquot of plasma $(500 \mu \mathrm{l})$ with $50 \mu \mathrm{l}$ of an antioxidant [sodium metabisulfite $10 \%(\mathrm{w} / \mathrm{v})$ ] were used for the assay of levodopa. After adding $10 \mu \mathrm{l}$ of internal standard (dihydroxybenzylamine, DHBA; $10 \mu \mathrm{g} / \mathrm{ml}$ ), levodopa was extracted from the plasma using an automated solid-phase extraction technique with alumina A cartridges (Set-Pak $100 \mathrm{mg}, 1 \mathrm{cc}$ Waters). Plasma concentrations of levodopa were determined using reversephase high-performance liquid chromatography (RP-HPLC) with electrochemical detection (Gilson), over a range of $50 \mathrm{ng} / \mathrm{ml}$ to $500 \mathrm{ng} / \mathrm{ml}$. For the determination of 3-OMD, samples were allowed to thaw at room temperature and plasma aliquots $(600 \mu \mathrm{l})$ were spiked with $12 \mu \mathrm{l}$ internal standard (metanephrine $50 \mu \mathrm{g} / \mathrm{ml}$ ). The deproteinization was performed by adding $88 \mu \mathrm{l} 0.01 \mathrm{M} \mathrm{HCl}$ solution and $300 \mu \mathrm{l} 1 \mathrm{M}$ PCA solution. After incubation on ice for $10 \mathrm{~min}$, samples were centrifuged and filtered. Aliquots of $50 \mu \mathrm{l}$ were injected in the chromatograph, and sample analysis was performed over a range of $50 \mathrm{ng} / \mathrm{ml}$ to $1000 \mathrm{ng} / \mathrm{ml}$.

\section{Assay of erythrocyte S-COMT activity}

The same blood samples taken for pharmacokinetic assessments were used for the preparation of washed erythrocytes for the assay of S-COMT activity in erythrocytes. After collection, the blood samples were immediately centrifuged $\left(1500 \times \mathrm{g}, 10 \mathrm{~min}, 4^{\circ} \mathrm{C}\right)$ and the resulting plasma and uppermost cell layer were removed. The tubes containing the erythrocytes were placed on ice and a volume of cold $0.9 \%$ sodium chloride solution equal to double that of cells was added. The cells were then mixed, centrifuged and washed using this procedure three times. Washed cells $(250 \mu \mathrm{l})$ in $2 \mathrm{ml}$ Eppendorf tubes were stored at $-70^{\circ} \mathrm{C}$ until required for analysis. S-COMT activity was determined according to the method of Schultz et al. [19] with minor modifications. In brief, pre-washed erythrocyte samples were haemolyzed with four volumes of ice-cold water. After vortexing, the samples were left standing on ice for $10 \mathrm{~min}$ and then centrifuged for $20 \mathrm{~min}$ at $4^{\circ} \mathrm{C}$ at $20,000 \times g$. The supernatant was used for S-COMT assay, which was carried out immediately after sample preparation. The incubation mixture contained $300 \mu \mathrm{l}$ enzyme preparation, $375 \mu$ incubation medium and $75 \mu \mathrm{l} 5 \mathrm{mM}$ adrenaline as the enzyme substrate. The final reaction volume $(750 \mu \mathrm{l})$ contained $100 \mathrm{mM}$ sodium phosphate buffer, pH 7.8, $2 \mathrm{mM} \mathrm{MgCl}$ and $200 \mu \mathrm{M} S$-adenosyl-L-methionine. The samples were incubated in a water bath at $37^{\circ} \mathrm{C}$ for $60 \mathrm{~min}$. The tubes were transferred to ice and the reaction was stopped by adding $75 \mu \mathrm{l}$ ice-cold $4 \mathrm{M}$ perchloric acid. After $10 \mathrm{~min}$, the samples were centrifuged $\left(5000 \times g, 10 \mathrm{~min}, 4^{\circ} \mathrm{C}\right)$ and $500-\mu 1$ aliquots of the supernatant, filtered on $0.22-\mu \mathrm{m}$ pore-size Spin-X filter tubes (Costar), were used for the assay of metanephrine by means of high-performance liquid chromatography (HPLC) with electrochemical detection, as previously described [20, 21]. S-COMT activity was expressed as the amount of metanephrine formed (as picomoles per milligram of protein per hour).

Analysis

\section{Pharmacokinetic and pharmacodynamic analysis}

The pharmacokinetic and pharmacodynamic variables were derived from non-compartmental analysis using WinNonlin Version 4.0 (Pharsight Co, Mountain View, CA, USA). The following variables for levodopa and 3-OMD were derived, where appropriate, from the individual plasma concentration-time: maximum observed dependent variable value $\left(\mathrm{C}_{\max }\right)$, the time of occurrence of $\mathrm{C}_{\max }\left(\mathrm{t}_{\max }\right)$, the area under the plasma concentration-time curve from time zero to the last sampling time at which the levodopa or 3-OMD concentration was at or above the limit of quantification, calculated by the linear trapezoidal rule $\left(\mathrm{AUC}_{0-\mathrm{t}}\right)$, the area under the plasma concentration-time curve from time zero to infinity, calculated from $\mathrm{AUC}_{0-\mathrm{t}}+\left(\mathrm{C}_{\text {last }} / \lambda_{\mathrm{z}}\right)$, where $\mathrm{C}_{\text {last }}$ is the last quantifiable levodopa or 3-OMD concentration $\left(\mathrm{AUC}_{0-\infty}\right)$, the apparent terminal rate constant calculated by log-linear regression of the terminal segment of the levodopa and 3-OMD plasma concentration versus time curve $\left(\lambda_{z}\right)$, the apparent terminal half-life $\left(t_{1 / 2}\right)$, calculated from $\ln 2 / \lambda_{\mathrm{z}}$. Mean ratios for the pharmacokinetic variables of levodopa and 3-OMD obtained following administration of Madopar 125 concomitantly with each different dose of BIA 3-202 versus those obtained after administration of Madopar 125 plus placebo were calculated. The following mean pharmacodynamic variables concerning COMT activity (expressed as metanephrine formed) were derived from the individual COMT activity profiles: maximum inhibition of COMT activity $\left(\mathrm{E}_{\mathrm{max}}\right)$, time to occurrence of $E_{\max }\left(t_{E \max }\right)$ and area under the effect-time curve (AUEC). The pre-dose value was taken as the baseline value $\left(\mathrm{E}_{0}\right)$.

The statistical analysis was performed using the Statistica software package (version 5.5, StatSoft Inc, Tulsa, OK, USA). For comparisons between BIA 3-202 and placebo, the analysis of variance (ANOVA) was carried out and, when appropriate, the Newman-Keuls test was used. In all statistical evaluations, significance was concluded if the $95 \%$ confidence interval $(95 \% \mathrm{CI})$ excluded the unit.

\section{Tolerability}

Individual and summary blood pressure, heart rate, ECG parameters, neurological examination and clinical laboratory data were presented in tabular form with mean, median, standard deviation and range (min and max) as appropriate. For the laboratory safety data, out of range values were flagged in the data listings and a list of clinically significantly abnormal values was presented. Adverse events were tabulated and summarised according to the Medical Dictionary for Regulatory Activities (MedDRA, version 4.0).

\section{Results}

A total of 18 subjects (12 male and 6 female) were enrolled in the study. The mean $( \pm \mathrm{SD})$ age, height and weight were $26.8 \pm 6.9$ years (range $20-45$ years), $1.70 \pm 0.09 \mathrm{~m}$ (range $1.54-1.84 \mathrm{~m}$ ), $69.1 \pm 8.7 \mathrm{~kg}$ (range $58.5-89.0 \mathrm{~kg}$ ), respectively.

\section{Pharmacokinetics}

\section{Plasma concentration versus time profiles and pharmacokinetics of levodopa}

Mean plasma levodopa concentration-time profiles and pharmacokinetic variables obtained following a single oral administration of Madopar 125 or placebo and BIA 3-202 (50, 100, 200 and $400 \mathrm{mg})$ are summarised in Fig. 1 and Table 1. Table 2 depicts the mean ratios of the pharmacokinetic variables obtained following administration of Madopar 125 plus BIA 3-202 over those obtained following administration of Madopar 125 plus placebo.

Mean $\mathrm{C}_{\max }$ values were attained at $1.0 \mathrm{~h}$ to $1.3 \mathrm{~h}$ post-dose. Thereafter, plasma levodopa concentrations declined with a mean elimination half-life increasing in a 
dose-dependent manner, ranging from $1.1 \mathrm{~h}$ (placebo) to $1.8 \mathrm{~h}$ (400 mg BIA 3-202). $\mathrm{C}_{\max }$ of levodopa did not differ between different doses of BIA 3-202 and between BIA 3-202 and placebo. A statistically significant increase in the extent of systemic exposure to levodopa $\left(\mathrm{AUC}_{0-\infty}\right)$ occurred at all doses of BIA 3-202 tested. The increase in levodopa AUC ranged from about $40 \%$ at $50 \mathrm{mg}$ (BIA 3-202/placebo ratios $=1.39$ ) to $80 \%$ at $400 \mathrm{mg}$ (BIA 3-202/placebo ratios $=1.80$ ). The increase

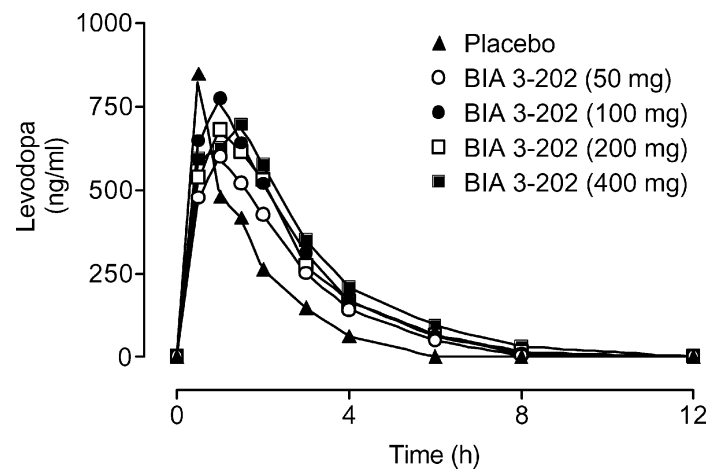

Fig. 1 Mean plasma levopopa concentration-time profiles following single oral administration of Madopar 125 concomitantly with placebo or BIA 3-202. Symbols indicate means of 18 subjects per group in levodopa AUC values was slightly higher at $100 \mathrm{mg}$ BIA 3-202 than that obtained with $200 \mathrm{mg}(60 \%$ versus $52 \%)$.

\section{Plasma concentration versus time profiles and pharmacokinetic of 3-OMD}

Mean plasma 3-OMD concentration-time profiles and pharmacokinetic variables are presented in Fig. 2 and Table 3, respectively. BIA 3-202 was found to decrease in a dose proportional manner the mean $\mathrm{C}_{\max }$ and $\mathrm{AUC}_{0-\infty}$ values, with differences versus placebo being statistically significant for all the doses tested (Table 2).

\section{Pharmacodynamics}

Mean COMT inhibition profiles and pharmacodynamic variables for COMT inhibition are summarised in Fig. 3 and Table 4. Assuming the pre-dose metanephrine formed as baseline, the maximum COMT inhibition $\left(\mathrm{E}_{\max }\right)$ occurred between $1.4 \mathrm{~h}$ and $2.0 \mathrm{~h}$ post-dose $\left(\mathrm{t}_{\text {Emax }}\right)$, and ranged from $57 \%(50 \mathrm{mg})$ to $84 \%(400 \mathrm{mg})$. At all doses tested, BIA 3-202 significantly $(P<0.01)$ decreased COMT activity.

Table 1 Mean (coefficient of variation, \%) pharmacokinetic variables of levodopa following single oral administration of Madopar 125 concomitantly with placebo or BIA 3-202 $\left(n=18\right.$ unless otherwise noted). $C_{\max }$ peak plasma concentration, $t_{\max }$ time to reach $\mathrm{C}_{\max }, A U C$ area under concentration-time curve, $t_{1 / 2}$ half-life

\begin{tabular}{lllllll}
\hline Dose & $\begin{array}{l}\mathrm{C}_{\max } \\
(\mathrm{ng} / \mathrm{ml})\end{array}$ & $\begin{array}{l}\mathrm{t}_{\max } \\
(\mathrm{h})\end{array}$ & $\begin{array}{l}\mathrm{AUC}_{0-\mathrm{t}} \\
(\mathrm{ng} \mathrm{h} / \mathrm{ml})\end{array}$ & $\begin{array}{l}\mathrm{AUC} \text { - } \\
(\mathrm{ng} \mathrm{h} / \mathrm{ml})\end{array}$ & $\begin{array}{l}\lambda_{\mathrm{z}} \\
(1 / \mathrm{h})\end{array}$ \\
\hline Placebo & $1091(80)$ & $1.0(0.5-2.0)$ & $1240(48)$ & $1366(43)$ & $0.75(38)$ \\
$50 \mathrm{mg}$ & $880(49)$ & $1.0(0.5-3.0)$ & $1596(41)$ & $1809(38)^{*}$ & $0.58(31)^{*}$ \\
$100 \mathrm{mg}$ & $1008(42)$ & $1.0(0.5-3.0)$ & $2048(45)$ & $2197(42)$ & $0.51(27)$ & $1.1(43)$ \\
$200 \mathrm{mg}$ & $876(38)$ & $1.0(0.5-3.0)$ & $1924(45)$ & $2083(42)$ & $0.47(22)$ & $1.4(22)$ \\
$400 \mathrm{mg}$ & $1075(47)$ & $1.3(0.5-3.0)$ & $2220(41)$ & $2416(39)$ & $0.40(24)$ \\
\hline
\end{tabular}

$\mathrm{t}_{\max }$ values are median with range values in parentheses

$*_{n}=17$ (terminal monoexponential phase could not be unambiguously identified in one subject)

Table 2 Mean ratios of the individual pharmacokinetic variables of levodopa and 3-O-methyl-levodopa (3-OMD) obtained following administration of Madopar 125 concomitantly with BIA 3-202 versus Madopar 125 plus placebo ( $n=18$ unless otherwise noted) $C_{\text {max }}$ peak plasma concentration, $A U C$ area under concentrationtime curve, $t_{1 / 2}$ half-life

\begin{tabular}{|c|c|c|c|c|c|c|}
\hline & \multicolumn{3}{|l|}{ Levodopa } & \multicolumn{3}{|l|}{ 3-OMD } \\
\hline & $\mathrm{C}_{\max }$ & $\mathrm{AUC}_{0-\infty}$ & $\mathrm{t}_{1 / 2}$ & $\mathrm{C}_{\max }$ & $\mathrm{AUC}_{0-\infty}$ & $t_{1 / 2}$ \\
\hline $50 \mathrm{mg}$ & $\begin{array}{l}0.91 \\
(0.58,1.44)\end{array}$ & $\begin{array}{l}1.39 \\
(1.06,1.69)^{*}\end{array}$ & $\begin{array}{l}1.23 \\
(0.45-3.18)^{*}\end{array}$ & $\begin{array}{l}0.57 \\
(0.45,0.71)\end{array}$ & $\begin{array}{l}0.67 \\
(0.54,0.84)^{* *}\end{array}$ & $\begin{array}{l}1.12 \\
(0.45-2.01)^{* *}\end{array}$ \\
\hline $100 \mathrm{mg}$ & $\begin{array}{l}1.06 \\
(0.69,1.63)\end{array}$ & $\begin{array}{l}1.60 \\
(1.27,1.98)\end{array}$ & $\begin{array}{l}1.58 \\
(0.54-2.97)\end{array}$ & $\begin{array}{l}0.41 \\
(0.35,0.48)\end{array}$ & $\begin{array}{l}0.52 \\
(0.43,0.63)\end{array}$ & $\begin{array}{l}1.31 \\
(0.62-1.82)\end{array}$ \\
\hline $200 \mathrm{mg}$ & $\begin{array}{l}0.93 \\
(0.83,1.56)\end{array}$ & $\begin{array}{l}1.52 \\
(1.22,1.90)\end{array}$ & $\begin{array}{l}1.56 \\
(0.58-3.53)\end{array}$ & $\begin{array}{l}0.35 \\
(0.27,0.45)\end{array}$ & $\begin{array}{l}0.42 \\
(0.32,0.53)^{*}\end{array}$ & $\begin{array}{l}1.40 \\
(0.50-2.17)^{*}\end{array}$ \\
\hline $400 \mathrm{mg}$ & $\begin{array}{l}1.12 \\
(0.74,1.70)\end{array}$ & $\begin{array}{l}1.80 \\
(1.43,2.22)\end{array}$ & $\begin{array}{l}1.65 \\
(0.68-3.70)\end{array}$ & $\begin{array}{l}0.24 \\
(0.18,0.32)\end{array}$ & $\begin{array}{l}0.40 \\
(0.30,0.51)^{* *}\end{array}$ & $\begin{array}{l}1.78 \\
(0.92-2.84)^{* *}\end{array}$ \\
\hline
\end{tabular}

$\mathrm{C}_{\max }$ and $\mathrm{AUC}_{0-\infty}$ ratios are presented as geometric means and $95 \%$ confidence intervals $\mathrm{t}_{\max }$ are presented as median with range values in parentheses $* n=17, * * n=16$ 


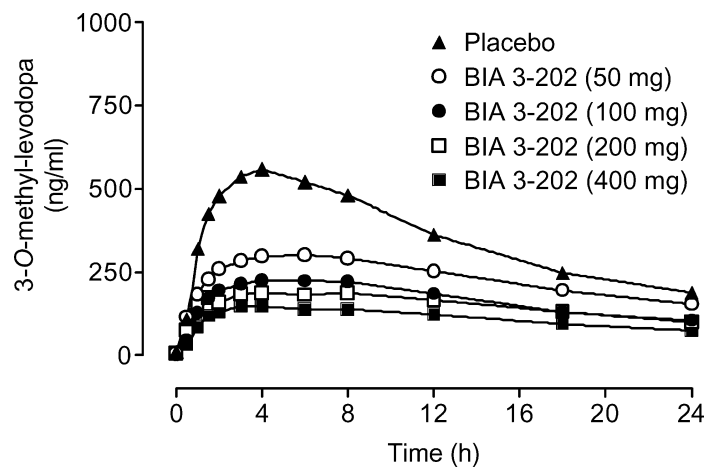

Fig. 2 Mean plasma 3-O-mehtyl-levodopa concentration-time profiles following single oral administration of Madopar 125 concomitantly with placebo or BIA 3-202. Symbols indicate means of 18 subjects per group

Table 3 Mean (coefficient of variation, \%) pharmacokinetic variables of 3-O-methyl-levodopa following single oral administration of Madopar 125 concomitantly with placebo and BIA 3-202 $(n=18$ unless otherwise noted). $C_{\max }$ peak plasma concentration, $t_{\max }$ time to reach $\mathrm{C}_{\max }, A U C$ area under concentration-time curve, $t_{1 / 2}$ halflife

\begin{tabular}{lllll}
\hline & $\begin{array}{l}\mathrm{C}_{\max } \\
(\mathrm{ng} / \mathrm{ml})\end{array}$ & $\begin{array}{l}\mathrm{t}_{\max } \\
(\mathrm{h})\end{array}$ & $\begin{array}{l}\mathrm{AUC}_{0-\infty} \\
(\mathrm{ng} \mathrm{h} / \mathrm{ml})\end{array}$ & $\begin{array}{l}\mathrm{t}_{1 / 2} \\
(\mathrm{~h})\end{array}$ \\
\hline Placebo & $579(26)$ & $4.0(1.0-6.0)$ & $11717(26)$ & $11.7(26)$ \\
$50 \mathrm{mg}$ & $333(35)$ & $5.0(0.5-8.0)$ & $7278(58)^{* *}$ & $12.1(46)^{* *}$ \\
$100 \mathrm{mg}$ & $239(27)$ & $4.0(1.0-8.0)$ & $6189(34)$ & $14.4(18)$ \\
$200 \mathrm{mg}$ & $228(62)$ & $5.0(0.5-12.0)$ & $4989(61)^{*}$ & $13.8(37)^{*}$ \\
$400 \mathrm{mg}$ & $163(69)$ & $4.0(1.0-12.0)$ & $4479(74)^{* *}$ & $16.9(45)^{* *}$ \\
\hline
\end{tabular}

$\mathrm{t}_{\max }$ values are median with range values in parentheses

$* n=17 ; * * n=16$ (terminal monoexponential phase could not be unambiguously identified in one and two subjects, respectively)

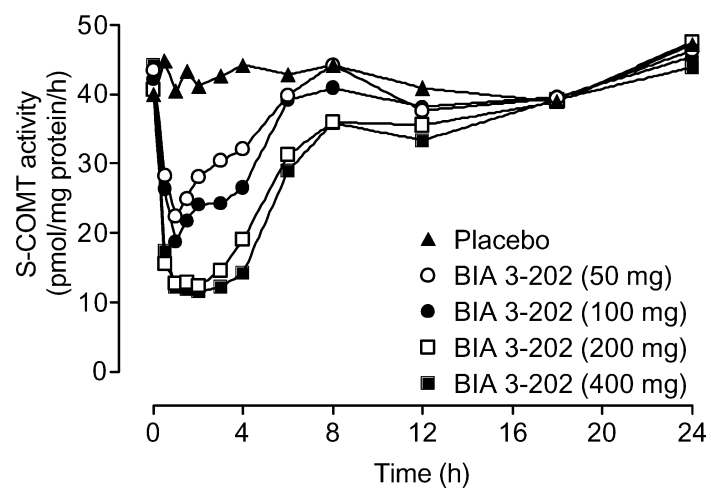

Fig. 3 Mean S-COMT activity (pmol/mg protein/h) profile from baseline (pre-dose) following single oral administration of Madopar 125 concomitantly with placebo or BIA 3-202. Symbols indicate means of 18 subjects per group

\section{Tolerability}

During the course of the study, $17(94.4 \%)$ of the 18 subjects who participated reported a total of 48 adverse events. From these adverse events, 32 were assessed as possibly related to treatments (Madopar 125 and BIA
3-202 or placebo) and 16 adverse events as not related. There were no serious adverse events, deaths or discontinuations due to adverse events. All adverse events were mild in severity except three adverse events reported by the same subject at different treatment periods: dizziness $(200 \mathrm{mg})$ and orthostatic hypotension $[100 \mathrm{mg}(22 \%$ decrease in systolic blood pressure $1 \mathrm{~h}$ after drug administration) and $400 \mathrm{mg}(21 \%$ decrease in systolic blood pressure $2 \mathrm{~h}$ after drug administration); on both occasions blood pressure returned to normal values within $1 \mathrm{~h}$ and $2 \mathrm{~h}$, respectively]. The most frequent adverse event was headache $(50 \mathrm{mg}$, four episodes; $100 \mathrm{mg}$, two episodes; $200 \mathrm{mg}$, one episode). No pattern suggesting a relationship between the dose of BIA 3-202 and occurrence of adverse events was detected. There were no clinically significant abnormalities in clinical laboratory safety tests, vital signs, and physical examination or ECG parameters.

\section{Discussion and conclusions}

In previous trials in healthy male subjects, BIA 3-202 was shown to be well tolerated and to inhibit COMT in a potent and reversible manner. The study reported here was the first aiming to explore the therapeutic potential of four different doses of BIA 3-202 administered together with a single dose of standard release levodopa/ benserazide.

The extent of systemic exposure to levodopa, measured by AUC, increased with increasing doses and the maximum increase in levodopa AUC values was $80 \%$, with the dose of $400 \mathrm{mg}$. Mean $\mathrm{t}_{\max }$ and $\mathrm{C}_{\max }$ of levodopa did not change significantly between different doses of BIA 3-202 or between BIA 3-202 and placebo. Plasma concentrations of levodopa declined with a mean apparent elimination half-life increasing in a dosedependent manner. At $100 \mathrm{mg}$ and $200 \mathrm{mg}$ BIA 3-202, the $t_{1 / 2}$ of levodopa increased approximately $60 \%$ versus placebo (ratios of 1.58 and 1.56, respectively). In a study by Kaakkola et al. [22], $200 \mathrm{mg}$ entacapone administered together with levodopa/benserazide increased the AUC of levodopa by $38 \%$. This might indicated that BIA 3-202 is more potent than entacapone at increasing exposure to levodopa. In the present study, the increasing exposure to levodopa with $50 \mathrm{mg}$ BIA 3-202 was similar to that obtained $200 \mathrm{mg}$ entacapone, and higher doses of BIA 3-202 (100, 200 and $400 \mathrm{mg})$ were clearly more efficacious. When compared with tolcapone, it seems that BIA 3-202 is less potent. In healthy volunteers that received tolcapone plus $100 / 25 \mathrm{mg}$ levodopa/benserazide, the mean AUC of levodopa approximately doubled with $200 \mathrm{mg}$ tolcapone; increases in the dose of tolcapone to $400 \mathrm{mg}$ and $800 \mathrm{mg}$ resulted in increases of levodopa AUC values by $90 \%$ and $70 \%$, respectively [23].

BIA 3-202 reduced $\mathrm{C}_{\max }$ and AUC values of 3-OMD in a dose-dependent manner. Statistically significant reductions were found for all doses tested. The 
Table 4 Pharmacodynamic variables for inhibition of S-COMT following single oral administration of Madopar 125 concomitantly with BIA 3-202

\begin{tabular}{llllll}
\hline Dose & $\begin{array}{l}\mathrm{E}_{0} \\
<(\mathrm{pmol} / \mathrm{mg} \text { protein/h) }\end{array}$ & $\begin{array}{l}\mathrm{E}_{\max } \\
(\mathrm{pmol} / \mathrm{mg} \text { protein/h) }\end{array}$ & $\begin{array}{l}\mathrm{t}_{\mathrm{Emax}} \\
(\mathrm{h})\end{array}$ & $\begin{array}{l}{\left[\left(\mathrm{E}_{0}-\mathrm{E}_{\max }\right) / \mathrm{E}_{0}\right] .100} \\
(\%)\end{array}$ & $\begin{array}{l}\text { AUEC } \\
(\mathrm{pmol} / \mathrm{mg} \mathrm{protein} / \mathrm{h} \mathrm{h})\end{array}$ \\
\hline 50 & $43.4 \pm 14.5$ & $18.4 \pm 6.9$ & $1.4 \pm 1.1$ & $57.2 \pm 10.6$ & $923 \pm 270$ \\
100 & $42.1 \pm 12.5$ & $13.0 \pm 5.3$ & $1.6 \pm 1.2$ & $69.2 \pm 8.8$ & $890 \pm 257$ \\
200 & $40.6 \pm 14.1$ & $8.0 \pm 3.6$ & $2.1 \pm 1.3$ & $80.0 \pm 5.5$ & $806 \pm 263$ \\
400 & $44.1 \pm 15.8$ & $7.0 \pm 4.4$ & $2.0 \pm 1.2$ & $83.8 \pm 9.9$ & $772 \pm 228$ \\
\hline
\end{tabular}

Values are presented as means \pm standard deviation $(n=18)$

formation of 3-OMD from levodopa is dependent on the COMT activity, particularly at the intestinal level, the main site of $O$-methylation of levodopa. The marked dose-dependent reduction in the 3-OMD levels indicates that BIA 3-202 may not only inhibit S-COMT in erythrocytes, but also in other organs, namely those rich in COMT such as the liver, kidney and intestine. In fact, BIA 3-202 was found to be equipotent at inhibiting liver S-COMT and erythrocyte S-COMT in the rat [17]. In the present study, $100 \mathrm{mg}$ and $200 \mathrm{mg}$ BIA 3-202 achieved a reduction in the AUC of 3-OMD of about $50 \%$ and $65 \%$, respectively.

The observed erythrocyte S-COMT activity indicates that BIA 3-202 at all doses tested induced a significant decrease in COMT activity. COMT inhibition ranged from $57 \%$ (50 mg) to $84 \%$ (400 mg). At $200 \mathrm{mg}$ BIA $3-202$, inhibition of S-COMT in erythrocytes reached the $80 \%$ reduction level, a value that is superior to that obtained with $200 \mathrm{mg}$ entacapone (approximately 65\%) [24] and slightly below that reported for tolcapone $(87 \%)$ [23].

Though elderly subjects, such as patients afflicted with Parkinson's disease, may handle levodopa differently, namely concerning its intestinal absorption [25], it is not anticipated that the efficacy of BIA 3-202 in preventing levodopa $O$-methylation may be compromised in parkinsonian patients. The $O$-methylation of levodopa has been demonstrated as a major event in the disposition of levodopa in young and elderly subjects and other COMT inhibitors, such as tolcapone and entacapone, effectively increase levodopa availability in an age-independent manner [26, 27, 28].

BIA 3-202 showed a favourable tolerability profile. The adverse events reported here were usually mild and transient. Most of the reported adverse events are characteristic of levodopa. The appearance of headache, dizziness and orthostatic hypotension in BIA 3-202 groups may be related to the increase in the AUC of levodopa and not necessarily be a consequence of a direct effect of BIA 3-202 administration. No correlation between adverse events and the dose of BIA 3-202 was apparent.

In conclusion, the novel COMT inhibitor BIA 3-202 was found to significantly increase the bioavailability of levodopa and to reduce the formation of 3-OMD when administered concomitantly with standard release levodopa/benserazide. Therefore, BIA 3-202 may have therapeutic utility as an adjunct to levodopa therapy in patients afflicted with Parkinson's disease. Clinical trials in patients with Parkinson's disease are, therefore, required to evaluate clinical improvements of BIA 3-202.

\section{References}

1. Hoehn MM (1992) The natural history of Parkinson's disease in the pre-levodopa and post-levodopa eras. Neurol Clin $10: 331-339$

2. Olanow CW, Watts RL, Koller WC (2001) An algorithm (decision tree) for the management of Parkinson's disease (2001) Treatment guidelines. Neurology 56:S1-S88

3. Paulson HL, Stern MB (1997) Clinical manifestations of Parkinson's disease. McGraw Hill, Toronto

4. Nutt JG, Fellman JH (1984) Pharmacokinetics of levodopa. Clin Neuropharmacol 7:35-49

5. Gomes P, Soares-da-Silva P (1999) Interaction between LDOPA and 3-O-methyl-L-DOPA for transport in immortalised rat capillary cerebral endothelial cells. Neuropharmacology 38:1371-1380

6. Chase TN (1998) The significance of continuous dopaminergic stimulation in the treatment of Parkinson's disease. Drugs $55: 1-9$

7. Olanow W, Schapira AH, Rascol O (2000) Continuous dopamine-receptor stimulation in early Parkinson's disease. Trends Neurosci 23:S117-S126

8. Factor SA, Molho ES, Feustel PJ, Brown DL, Evans SM (2001) Long-term comparative experience with tolcapone and entacapone in advanced Parkinson's disease. Clin Neuropharmacol 24:295-299

9. Lambert D, Waters $\mathrm{CH}$ (2000) Comparative tolerability of the newer generation antiparkinsonian agents. Drugs Aging 16:5565

10. Shepherd J, Clegg A (1999) Entacapone as an adjunctive treatment to levodopa in Parkinson's disease. Development and Evaluation Committee Report No. 104. The Wessex Institute for Health Research and Development, Southampton, pp 1-50

11. Männistö PT (1994) Clinical potential of catechol-O-methyltransferase (COMT) inhibitors as adjuvants in Parkinson's disease. CNS Drugs 1:172-179

12. Hauser RA, Molho E, Shale H, Pedder S, Dorflinger EE (1998) A pilot evaluation of the tolerability, safety, and efficacy of tolcapone alone and in combination with oral selegiline in untreated Parkinson's disease patients. Tolcapone de novo study group. Mov Disord 13:643-647

13. Bonifácio MJ, Vieira-Coelho MA, Soares-da-Silva P (2003) Kinetic inhibitory profile of BIA 3-202, a novel fast tightbinding, reversible and competitive catechol-O-methyltransferase inhibitor. Eur J Pharmacol 460:163-170

14. Learmonth DA, Vieira-Coelho MA, Benes J, Alves PC, Borges N, Freitas AP, da-Silva PS (2002) Synthesis of 1-(3,4-dihydroxy-5-nitrophenyl)-2-phenyl-ethanone and derivatives as potent and long-acting peripheral inhibitors of catechol-Omethyltransferase. J Med Chem 45:685-695 
15. Parada A, Loureiro AI, Vieira-Coelho MA, Hainzl D, Soaresda-Silva P (2001) BIA 3-202, a novel catechol-O-methyltransferase inhibitor, enhances the availability of L-DOPA to the brain and reduces its O-methylation. Eur J Pharmacol 420:27-32

16. Parada A, Soares-da-Silva P (2003) BIA 3-202, a novel catechol-O-methyltransferase inhibitor, reduces the peripheral Omethylation of L-DOPA and enhances its availability to the brain. Pharmacology 68:29-37

17. Soares-da-Silva P, Vieira-Coelho MA, Parada A (2003) BIA 3202 is an effective inhibitor of erythrocyte and liver soluble catechol-O-methyltransferase and enhances the availability of L-DOPA to the brain. Pharmacol Toxicol 92:272-278

18. Almeida L, Soares-da-Silva P (2003) Pharmacokinetics and pharmacodynamics of BIA 3-202, a novel COMT inhibitor, during first administration to humans. Drugs R D 4:207-217

19. Schultz E, Nissinen E, Kaakkola S (1989) Determination of catechol-O-methyltransferase activity in erythrocytes by high performance liquid chromatography with electrochemical detection. Biomed Chromatogr 3:64-67

20. Vieira-Coelho MA, Soares-da-Silva P (1996) Ontogenic aspects of liver and kidney catechol-O-methyltransferase sensitivity to tolcapone. Br J Pharmacol 117:516-520

21. Vieira-Coelho MA, Soares-da-Silva P (1999) Effects of tolcapone upon soluble and membrane-bound brain and liver catechol-O-methyltransferase. Brain Res 821:69-78
22. Kaakkola S, Teravainen H, Ahtila S, Rita H, Gordin A (1994) Effect of entacapone, a COMT inhibitor, on clinical disability and levodopa metabolism in parkinsonian patients. Neurology 44:77-80

23. Dingemanse J, Jorga K, Zürcher G, Schmitt M, Sedek G, Da Prada M, Van Brummelen P (1995) Pharmacokinetic-pharmacodynamic interaction between the COMT inhibitor tolcapone and single-dose levodopa. Br J Clin Pharmacol 40:253262

24. Keranen T, Gordin A, Karlsson M, Korpela K, Pentikainen PJ, Rita H, Schultz E, Seppala L, Wikberg T (1994) Inhibition of soluble catechol-O-methyltransferase and single-dose pharmacokinetics after oral and intravenous administration of entacapone. Eur J Clin Pharmacol 46:151-157

25. Sage JI, Mark MH (1994) Pharmacokinetics of continuousrelease carbidopa/levodopa. Clin Neuropharmacol 17[Suppl 2]:S1-S6

26. Kurth MC, Adler CH (1998) COMT inhibition: a new treatment strategy for Parkinson's disease. Neurology 50:S3-S14

27. Bonifati V, Meco G (1999) New, selective catechol-O-methyltransferase inhibitors as therapeutic agents in Parkinson's disease. Pharmacol Ther 81:1-36

28. Kaakkola S (2000) Clinical pharmacology, therapeutic use and potential of COMT inhibitors in Parkinson's disease. Drugs 59:1233-1250 